\title{
Taking the Economic Pulse: An Improved Tool to Help Track Economic Cycles in Canada
}

\author{
by
}

Jeremy Kronick

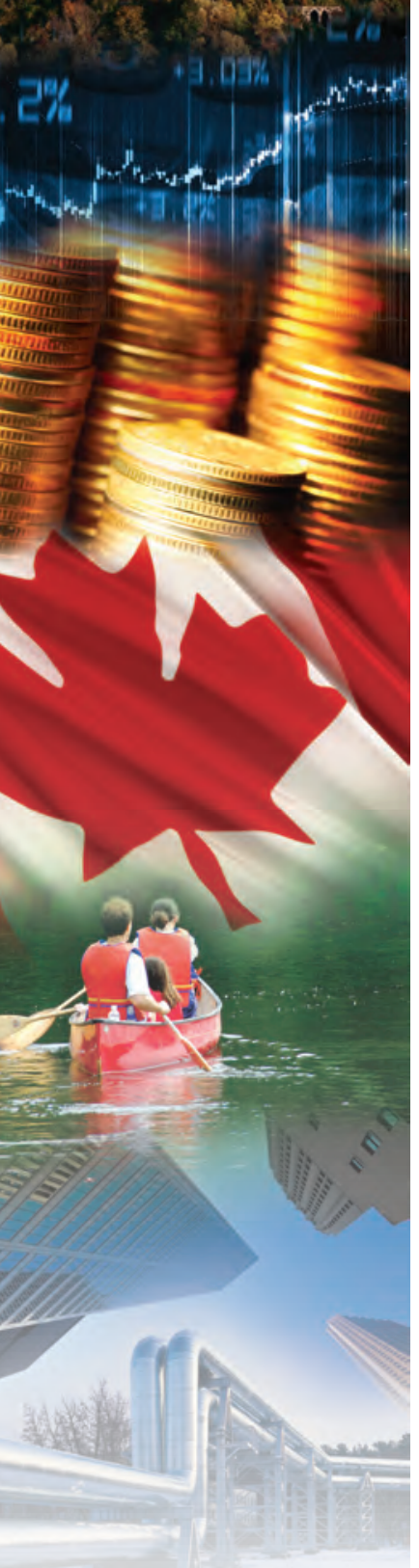

- Policymakers and economists need a reliable way to measure the extent to which economic shocks, booms and busts spread throughout an economy. Such a "diffusion index" is an important contributor to the determination of the onset, length and breadth of recessions and recoveries.

- Statistics Canada, which had produced a diffusion index for many years, stopped doing so in 2012. This paper, undertaken under the aegis of the C.D. Howe Institute's Business Cycle Council, fills this data gap by generating new, improved ways of measuring the diffusion of ripples, booms or busts in the Canadian economy.

- The first and primary method uses a standard statistical methodology - principal components analysis - that more accurately identifies the underlying trend and co-movements in the data across industries. The second method, called the "median cut-off" or "MCO" approach, includes only industries that are above the median size in terms of contribution to overall GDP.

- Both new measures provide useful additional information. For example, the principal components diffusion index indicates an additional quarter of greater contractionary than expansionary industries at the end of the 2008-2009 recession. Also, all the methodologies suggest the negative oil price shock that led to a contractionary economy in the first half of 2015 was not diffuse enough to warrant a recessionary call.

When Canadians think about negative economic shocks, such as the recent collapse in oil prices, many want to know whether the damage will be isolated or widely spread. To provide an answer, economists use a "diffusion index" that conveys in a single number the extent to which the downs (or ups) of an economy are widespread in any given period. Statistics Canada produced a diffusion index for many years following Cross' (2004) methodology. Unfortunately, Statistics Canada stopped producing the diffusion index in 2012. This paper, undertaken under the aegis of the C.D.

The author would like to thank Craig Alexander, Daniel Schwanen, Ben Dachis and Colin Busby of the C.D. Howe Institute, as well as Angelo Melino, Philip Cross, Eric Lascelles, Randall Bartlett, and anonymous reviewers for their helpful suggestions. I retain full responsibility for any remaining errors or omissions. 
Howe Institute's Business Cycle Council, fills this data gap by generating new, improved ways of measuring the diffusion of ripples, booms or busts in the Canadian economy.

Having robust, methodologically sound data on diffusion is important for the proper understanding of business cycles, including the identification of recessions. This paper presents two methodologies that represent improvements over the old Statistics Canada method for calculating diffusion indices. The first and primary method uses a standard statistical methodology - principal components analysis - that more accurately identifies the underlying trend and co-movements in the data across industries. The hope is that the first "principal component" explains the bulk of the variation in the data. The second method, which I label the "median cut-off" or "MCO" approach, includes only industries that are above the median size in terms of contribution to overall GDP. With these methods providing a clearer picture of the level of diffusion in economic activity, a more reliable picture emerges as to when, and what type of, fiscal and/or monetary stimulus or restraint is appropriate. Specifically, policymakers will be able to better determine whether acting on a particular economic shock is required and whether blunt instruments that impact most, if not all, sectors are appropriate, or whether targeted responses are more likely to create the desired outcomes.

Over the 2007-2015 period analyzed in this paper, the quarters identified by the new indices as having more contracting than expanding industries closely matched those generated using Cross' (2004) methodology. Interestingly, all three methodologies suggest that the negative oil price shock that led to a contractionary economy in the first half of 2015 was not diffuse enough to warrant a recessionary call.

That said, in addition to being more methodologically sound, the new indices produced important differences that will be valuable for business cycle analysts and policymakers alike. Specifically, the principal components diffusion index suggests that the 2008-2009 recession lasted slightly longer than previously thought, and the median cut-off diffusion index is more volatile than the others, implying greater synchronicity, or co-movement, between larger Canadian industries in both a positive and negative direction.

\section{Measuring Diffusion: Past, Present, and Future}

This section will first describe the unweighted diffusion index from Cross (2004) and, next, how I adapt the method to produce a baseline version for the purposes of comparison. I then present the case for principal components analysis being a statistical improvement in calculating the diffusion index. ${ }^{1}$ The final part of this section discusses how the potential arbitrariness of industry data breakdowns in the unweighted diffusion index can be avoided by continuing to follow the Cross (2004) methodology while looking only at the subset of all industries measured by Statistics Canada that are of median or larger size; i.e., the median cut-off approach.

\section{Origins of the Unweighted Methodology}

Diffusion indices have been around as an analytical tool since 1913. ${ }^{2}$ In Canada, Cross (2004) is the seminal attempt at a comprehensive diffusion index. At the time that paper was written, the analysis went back to 1981

1 Principal components analysis takes a large set of correlated observed variables and turns them into a smaller set of variables that are linearly uncorrelated, with each new variable representing a principal component. The first principal component is such that it accounts for the largest variance across the data. The second component will account for the next largest variance amongst the data, and so on.

2 Developed as far back as Mitchell 1913. 
and the decision on which industries to use was based on the length of time for which seasonally adjusted data at the 2 or 3 Standard Industrial Classification (SIC) digit level was available. The index was calculated using 83 industries.

The index was built as follows: expanding industries over a given period received a score of 100, those falling received a score of zero, and those with unchanged output received a score of $50 .{ }^{3}$ An average was then calculated using the scores for each industry. No weights were attached to sectoral changes to reflect the size of the industry as this would simply get closer to recalculating changes in overall real GDP, which would defeat the purpose of understanding the diffusion of economic activity.

An overall average of 50 indicated an equal number of expanding and contracting industries in a given period. A score above 50 indicated more expanding than contracting industries and a score below 50 the opposite. The series was calculated monthly generating an unsmoothed index. A five-month moving average ${ }^{4}$ version was also calculated to smooth out the dataset and avoid putting too much emphasis on a given month. A quarterly version of the unsmoothed index (see Cross and Bergevin 2012) can be calculated as well by averaging the values for the diffusion index across the three months of the relevant quarter.

\section{The "Baseline Version"}

In this paper, I use the chain-weighted ${ }^{5}$ sectoral data by North American Industrial Classification System (NAICS) code, at the three-digit level. ${ }^{6}$ One major advantage in using these more recent data over the data in Cross (2004) is that the breakdown of industries is essentially one-third goods and two-thirds services, reflecting the true size of these sectors in the overall economy. The older data had the reverse split between goods and services. ${ }^{7}$ A simple unweighted version can then be calculated using the 101 industries that arise from the threedigit breakdown. I label this unweighted diffusion index the "baseline" version. The index is first calculated at a monthly frequency before averaging the three months of a given quarter to generate the quarterly results.

3 The Conference Board of Canada (2012) describes 'unchanged' as being a change that is less than the absolute value of 0.05. I run the results for the unweighted indices with both a threshold of 0.05 and no threshold at all, and found no difference between these two calculations, either regarding the quarters in which a majority of industries are contracting, or in the average value of the diffusion indices. To avoid arbitrary thresholds the results are presented with no threshold.

4 Cross (2004) found that five-month moving averages lead to lower standard deviations versus the more traditional three-month and six-month moving averages.

5 Chain-weighted means that the real GDP index is adjusted for the fact that product substitutions occur over time in line with associated price changes and that consumers change their spending behavior accordingly, instead of relying on a fixed base-year basket of goods with fixed prices. In 2013, Statistics Canada started deriving monthly GDP data by chaining a Laspeyres fixed weighted volume index to the prior period, moving away from the pure chain-weighted index. As we simply analyze change from one quarter to the next, and provide a 100, 50 , or 0 value to each change, the adoption of a new statistical technique to measure GDP should not have a significant effect.

6 I use the four-digit level in cases where industry breakdowns skip from the two-digit to four-digit level. I use a twodigit figure in the one instance where only a two-digit level industry was available (Management of companies and enterprises).

7 Cross (2004) mentions that the reason he does not use the chain-weighted NAICS data was that there was not enough data at the time of the writing as it only went back to 1997. 


\section{A Better Way: The Principal Components Analysis Methodology}

The unweighted version of diffusion provides a pure measure of breadth of changes in economic output, as it abstracts completely from both the depth and amplitude of economic growth. However, there are statistical techniques that can yield a truer measure of the underlying trend in the economy by better taking sectoral comovements into account. One of those statistical techniques is principal components analysis.

To allow comparison between the principal components analysis and the baseline version, I assign to expanding, neutral, and contracting industries the same 100, 50 and 0 breakdown described above. By defining industry growth in this fashion, the principal components diffusion index can also be thought of as representing the overall predicted percentage of expanding industries in a given month. The idea behind principal components is that the overall percentage of expanding industries in a given period can be represented by a common component, or a business cycle shock, and idiosyncratic shocks, which one would not expect to be diffuse, e.g., a strike or weather-related event. Therefore, the principal components diffusion index will remove the idiosyncratic shocks in order to focus exclusively on the true business cycle shocks. Box 1 provides a more complete analysis on the comparability between the unweighted and principal components analyses.

I then generate a quarterly version of the principal component diffusion index by averaging the three months comprising the relevant quarter.

\section{A Third Option: The Median Cut-Off Diffusion Index}

The principal components index, while more statistically sound, has by definition lower volatility compared with the baseline version. ${ }^{8}$ Therefore, as it stands, the baseline version tells us more about how volatile co-movement is likely to be. A key data issue, however, arises from the baseline version. Specifically, Statistics Canada produces greater breakdowns of sub-sectors for some industries than for others. There is not always economic reasoning for including these greater breakdowns, and doing so will unnecessarily put more weight in the diffusion index on particular sectors of the economy. ${ }^{9}$

To account for this challenge, this paper calculates a second unweighted version, where the first step is to estimate the percent share of GDP for each sub-industry, then calculate the median of these shares, and finally, calculate the final diffusion index using Cross' (2004) methodology but only including the 51 industries that sit above that median. I label this unweighted diffusion index the "median cut-off or MCO" version. It is worth noting that the composition of industries making up the median version remains one-third goods and two-thirds services.

8 Proof is available on request.

9 Note that there is one strong reason for some industries having greater breakdowns than others. Specifically, if an industry is more cyclical it is likely, and useful, that there be more data on that industry. Goods industries tend to be more cyclical than services industries (Statistics Canada 2009 references the increased cyclicality of manufacturing compared with the overall economy.). However, as noted in the text, the median cut-off index I present in this paper reduces the number of industries used, but does not change the overall goods-services breakdown in my sample. This suggests that the availability of greater sub-industry data breakdowns in certain industries is not entirely due to an attempt to focus more on cyclical industries. 


\section{Box 1: The Principal Components Index, Methodology}

Define $Y_{t}=\left(Y_{1 t} \ldots Y_{G t}\right)^{\prime}$ where $Y_{g, t}$ represents whether the output of a particular industry $\mathrm{g}$, is expanding, constant, or contracting in period $t$. Depending on which it is, $Y_{g, t}$ takes on values 100,50 , or 0 . The Cross unweighted version is therefore:

$E\left(Y_{t}\right) \equiv \frac{1}{G} \sum_{g=1}^{G} Y_{g t}$ in each period $t$, with $\mathrm{G}$ being the number of industries.

Principal components analysis allows one to rewrite $Y_{t}$ as a linear combination of uncorrelated components. Without getting into complicated proofs, $Y_{t}$ can be rewritten as:

$Y_{t}=w^{*} w^{\prime} Y_{t}+e_{t}$ or $Y_{t}=w^{*} B_{t}+e_{t}$

where $w$ is a vector representing the weights corresponding to the first component generated by estimating principal components, $w$ ' representing the transpose of the vector $w$, and $B_{t}$ now represents

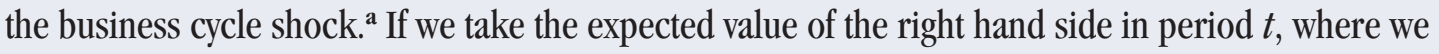
assume the expected value of the error term is zero, we get

$$
E\left(Y_{t}\right)=\frac{1}{G} \sum_{g=1}^{G} Y_{g t}=E\left(w^{*} B_{t}\right)=\frac{1}{G} \sum_{g=1}^{G}\left(w^{*} B_{g t}\right) .
$$

Therefore, since we can interpret the unweighted diffusion index as the percentage of industries in a given quarter that are expanding, we can make a similar statement regarding the interpretation of the principal components version. Specifically, the principal components diffusion index represents the predicted percentage of industries that are expanding in a given quarter, given the common component $B_{t}$. The preference for principal components analysis is due to the fact that, estimated correctly, it filters out idiosyncratic shocks, $e_{t}$, such as weather, strikes, etc. and instead focuses on the true business cycle shock $B_{t}$.

a I check and confirm that the first component explains the majority of the variation in the data.

\section{Comparing Results}

This section presents the results for the baseline diffusion index developed for this study, and the indices calculated using the two methodological improvements I introduced above. The diffusion indices are calculated over 2007-2015 due to the large change in available industries after 2007 at the three-digit level, from the earlier period dating back to 1997 when chain-weighted sectoral data were first made available. ${ }^{10}$

10 To go back to 1997 would shrink the sectors in half, which would still make the unweighted versions possible where one simply acknowledges that the index is calculated differently over the two subsamples, but would be impossible using principal components analysis as the smaller sample would be forced on the entire estimation period. 


\section{Figure 1: Comparison - Baseline and Median Cut-Off Diffusion Indices}

*Correlation: Baseline-Median Cut-off $=0.95$

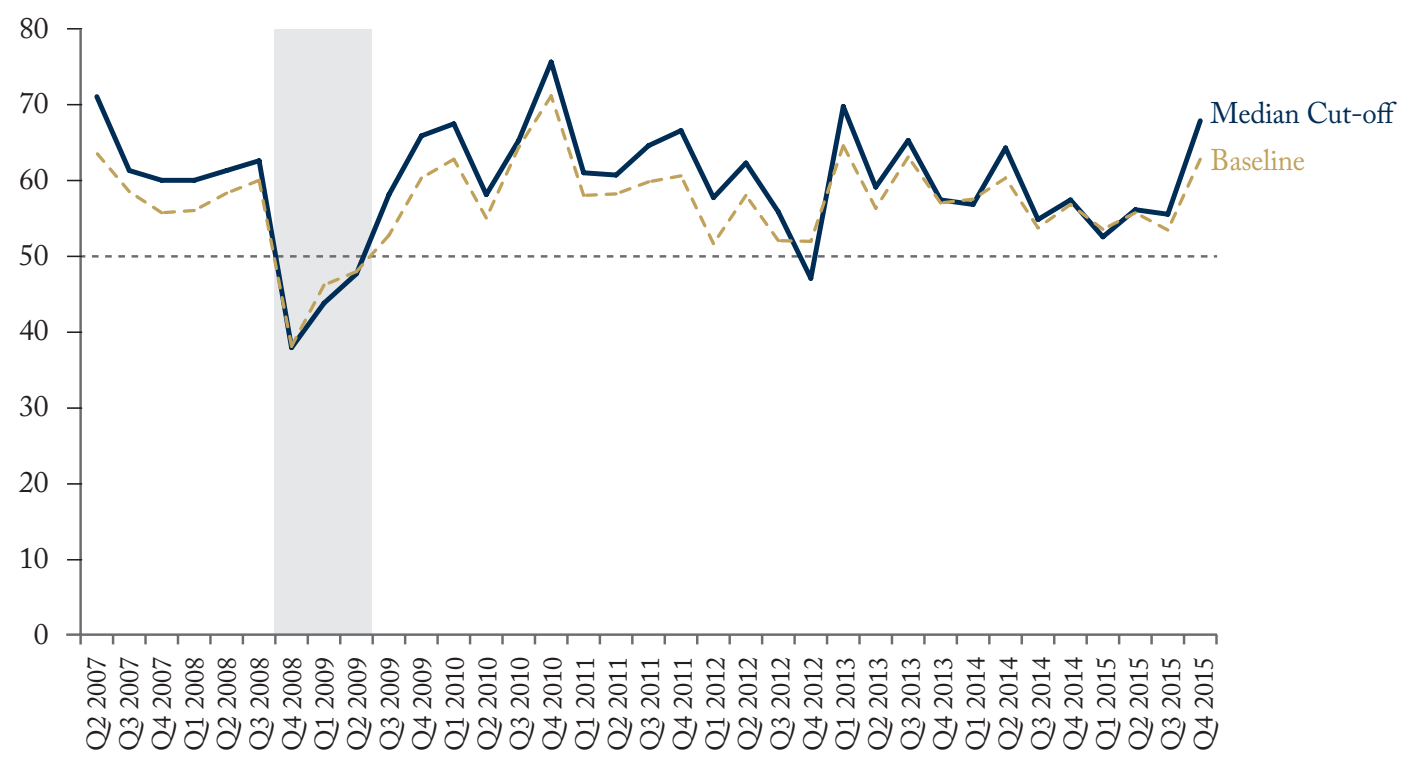

Note: Shaded area represents recessionary quarters as identified by Cross and Bergevin (2012). Source: Author's calculations.

Figure 1 compares the baseline unweighted diffusion index to the MCO version.

These results tell us that the quarters in which there are a majority of contracting industries are essentially identical across both unweighted diffusion indices. Q4 2012 is the only additional quarter with greater industry contractions using the MCO approach. The implication is that both measures produce similar conclusions regarding the breadth of economic activity in a given quarter.

Note that there is increased volatility with the MCO index, meaning that large industries in Canada are more likely to rise and fall at the same time than potentially randomly chosen industries. ${ }^{11}$ For example, there was a fall in goods trade in Q4 2012 led in part by decreasing auto and consumer goods exports. Given the size of these industries, there were large knock-on effects, contributing to the significant amount of contracting industries in this quarter. As a result, the MCO diffusion index fell below 50, something we did not see in the baseline index.

11 With the exception of Q1 2014 and Q1 2015, the median cut-off index values are greater than the baseline's when both diffusion indices are above 50, indicating a higher degree of growth industries, and when the indices fall below 50, the median cut-off index values are smaller than the baseline's, implying a higher degree of contracting industries. 


\section{Figure 2: Comparison - Principal Components versus Unweighted Diffusion Indices}

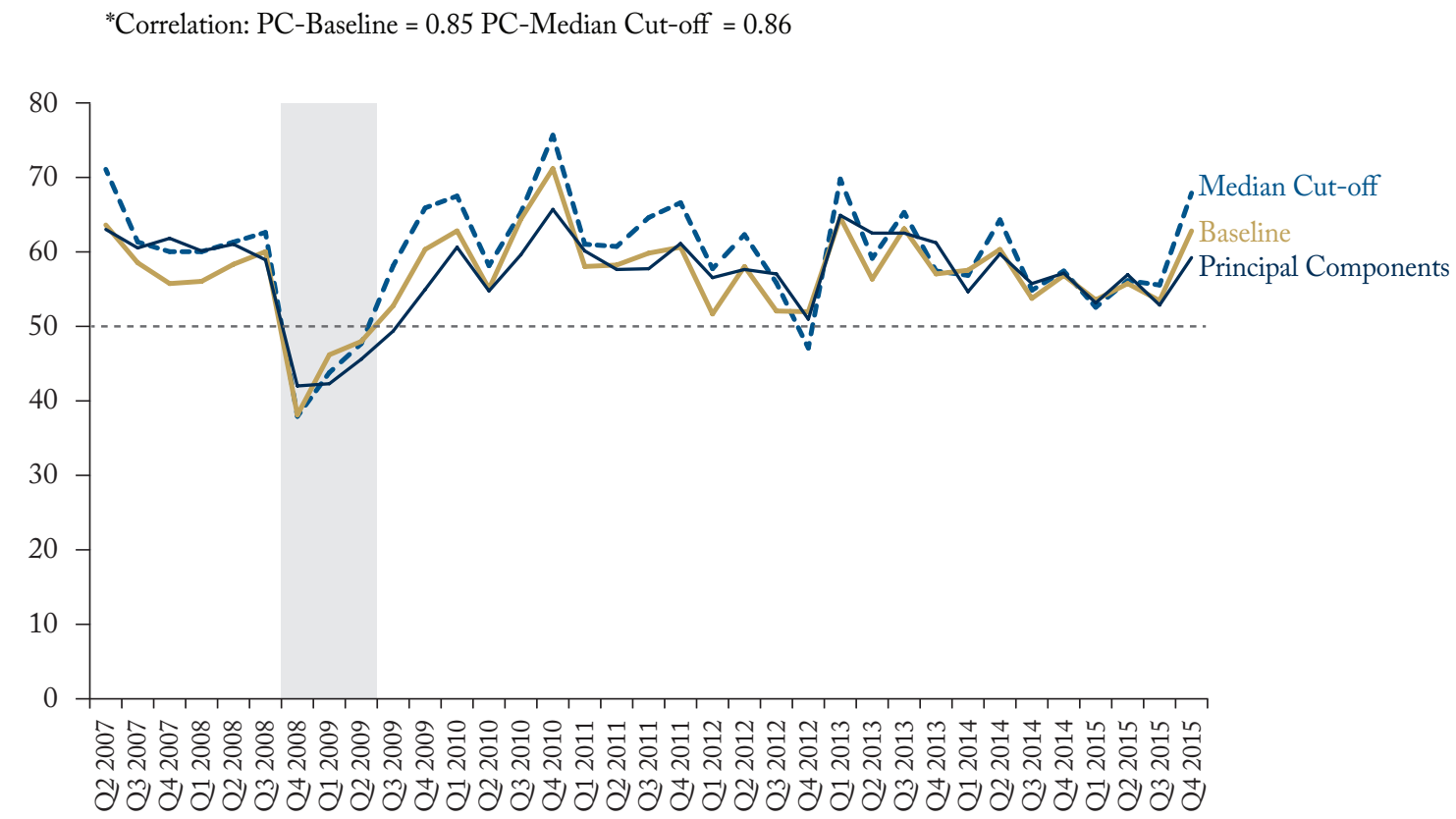

Note: Shaded area represents recessionary quarters as identified by Cross and Bergevin (2012). Source: Author's calculations.

\section{Interpreting the Principal Components Analysis Diffusion Index}

Figure 2 overlays the principal components version of the index with the two unweighted versions. A few things stand out. First, there is high correlation between the principal components version and both unweighted versions. This is a strong result as it implies that the one common component explains the bulk of the variation of the overall economy and therefore does a good job of extracting the true commonalities between sectors.

Furthermore, the principal components diffusion index indicates an additional quarter of greater contractionary than expansionary industries at the end of the 2008-2009 recession. Whereas both unweighted versions suggest that the bulk of industries had become expansionary by Q3 2009, the principal components index indicates that a slight majority of industries were still in contraction. Business cycle analysts, including the C.D. Howe Institute's Business Cycle Council, can benefit from having a clearer understanding of exactly when Canada's economy escaped the Great Recession and what the important factors were in this respect.

\section{Understanding Business Cycles}

As mentioned above, the diffusion index is an important tool for understanding business cycles, including recession determination. Three elements define recessions: duration, amplitude, and breadth or scope (see 
Cross and Bergevin 2012). Diffusion index data are accompanied by data on real GDP and employment in order to evaluate whether economic activity has all three features in a given quarter. ${ }^{12}$ Therefore, an interesting question is what each measure tells us about potential recessionary quarters experienced in Canada over the 2007-2015 period under analysis.

For employment, this paper uses the employment growth rate as in Cross and Bergevin (2012). Similarly, for economic activity, this paper follows Cross and Bergevin and analyzes average real GDP growth, the two quarter average real GDP growth, as well as average per capita GDP growth for comparative and assessment purposes.

Table 1 in Appendix A lists each diffusion measure; i.e., baseline, principal components, and median cut-off, as well as data on employment and economic growth. All three diffusion indices have Q4 2008 to Q2 2009 as quarters with a majority of contracting industries. Both employment and economic growth are contractionary as well during this time, meaning that these quarters can be considered recessionary, consistent with Cross and Bergevin (2012). The baseline diffusion index has no other quarters where a majority of industries are contracting so this measure suggests there are no other recessionary quarters during the sample period.

The principal components diffusion index results, unlike the baseline index, indicate that slightly more industries than not continued to contract past Q2 2009 and into Q3 2009. Economic growth during this quarter was positive, though the two-quarter growth rate was negative. Employment growth was flat though the employment rate - not in the table - fell. Therefore, it is possible that we continued to be in a recession in Q3 2009.

The MCO diffusion index labeled Q4 2012 as having more contracting than expanding industries. However, as this was a one-off negatively diffuse quarter, and economic growth itself was positive both during Q4 2012, and the preceding and subsequent quarters, this episode did not amount to a recession.

Lastly, this paper notes that all three diffusion indices show a key reason why many economists hesitated to call the onset of a possible recession during 2015. However, the data used remain subject to revisions.

Overall, while the results are consistent across different methodologies during the period under analysis, the new measures introduced in this paper do lend more confidence to the interpretation of how widespread ups and downs in the economy were - one of the key indicators of expansionary or recessionary periods.

\section{Conclusion}

The impetus for creating the diffusion indices introduced in this E-Brief, and thus the paper's contribution, is twofold. First, this paper set out to fill a clear data gap created when Statistics Canada stopped producing its diffusion index. Second, policymakers need to have access to methodologically robust data on the diffusion of economic shocks in order to understand how and why economic activity spreads across sectors, and what that implies for blunt versus targeted economic policies. This paper improved on the available methodology by

12 After 1980, employment moved much more closely with business cycles than pre-1980, and therefore a higher weighting was placed on this variable than before. However, GDP remains the primary touchpoint for evaluating economic activity (see Cross and Bergevin 2012). 
(i) employing a more accurate statistical analysis of co-movement called principal components, and (ii) introducing the MCO diffusion index, an unweighted version with a potentially more balanced set of industries.

Both new measures identified issues with the baseline index and therefore provided useful additional information. In the case of the principal components diffusion index, we saw that the 2008-2009 recession may have lasted slightly longer than the baseline index would suggest. For the MCO diffusion index we saw increased volatility implying a greater degree of synchronicity across larger industries in Canada in both a positive and negative direction. Therefore, in addition to filling a data gap, the results in this paper provide policymakers and business cycle analysts with a more complete understanding of the general level of industry co-movement, and the specifics of how this played itself out in the recent Great Recession. 


\section{Appendix A}

\section{Table A1: Contractionary Quarters Under Different Diffusion Indices}

\begin{tabular}{|c|c|c|c|c|c|c|c|}
\hline & Baseline & $\begin{array}{c}\text { Principal } \\
\text { Components }\end{array}$ & $\begin{array}{l}\text { Median } \\
\text { Cut-Off }\end{array}$ & $\begin{array}{l}\text { Employment } \\
\text { Growth Rate }\end{array}$ & $\begin{array}{c}\text { Avg. GDP } \\
\text { Growth }\end{array}$ & $\begin{array}{c}2 \text { Quarter } \\
\text { Avg. Growth }\end{array}$ & $\begin{array}{c}\text { Per Capita } \\
\text { Avg. GDP } \\
\text { Growth }\end{array}$ \\
\hline Q2 2007 & 63.7 & 63.1 & 71.2 & 0.4 & 0.9 & 1.7 & 0.7 \\
\hline Q3 2007 & 58.6 & 60.6 & 61.4 & 0.7 & 0.4 & 1.4 & 0.1 \\
\hline Q4 2007 & 55.8 & 61.9 & 60.1 & 0.6 & 0.1 & 0.5 & -0.3 \\
\hline Q1 2008 & 56.1 & 60.2 & 60.1 & 0.3 & 0.1 & 0.1 & -0.1 \\
\hline Q2 2008 & 58.4 & 61.1 & 61.4 & 0.2 & 0.3 & 0.4 & 0.1 \\
\hline Q3 2008 & 60.1 & 59.0 & 62.7 & 0.1 & 0.7 & 1.0 & 0.3 \\
\hline Q4 2008 & 38.1 & 42.0 & 37.9 & -0.1 & -1.2 & -0.5 & -1.6 \\
\hline Q1 2009 & 46.2 & 42.3 & 43.8 & -1.3 & -2.3 & -3.5 & -2.5 \\
\hline Q2 2009 & 48.0 & 45.6 & 47.7 & -0.6 & -1.1 & -3.4 & -1.3 \\
\hline Q3 2009 & 52.8 & 49.4 & 58.2 & 0.0 & 0.4 & -0.6 & 0.1 \\
\hline Q4 2009 & 60.4 & 55.0 & 66.0 & 0.5 & 1.1 & 1.6 & 0.8 \\
\hline Q1 2010 & 62.9 & 60.7 & 67.6 & 0.5 & 1.4 & 2.5 & 1.2 \\
\hline Q2 2010 & 55.1 & 54.8 & 58.2 & 0.7 & 0.6 & 2.0 & 0.4 \\
\hline Q3 2010 & 64.5 & 59.7 & 65.4 & 0.2 & 0.7 & 1.3 & 0.3 \\
\hline Q4 2010 & 71.3 & 65.8 & 75.8 & 0.3 & 1.1 & 1.8 & 0.8 \\
\hline Q1 2011 & 58.1 & 60.2 & 61.1 & 0.5 & 0.8 & 2.0 & 0.7 \\
\hline Q2 2011 & 58.3 & 57.7 & 60.8 & 0.3 & 0.2 & 1.0 & 0.0 \\
\hline Q3 2011 & 59.9 & 57.8 & 64.7 & 0.4 & 1.4 & 1.6 & 1.1 \\
\hline Q4 2011 & 60.7 & 61.2 & 66.7 & 0.0 & 0.7 & 2.1 & 0.3 \\
\hline
\end{tabular}




\section{Table A1: continued}

\begin{tabular}{lccccccc} 
& Baseline & $\begin{array}{c}\text { Principal } \\
\text { Components }\end{array}$ & $\begin{array}{c}\text { Median } \\
\text { Cut-Off }\end{array}$ & $\begin{array}{c}\text { Employment } \\
\text { Growth Rate }\end{array}$ & $\begin{array}{c}\text { Avg. GDP } \\
\text { Growth }\end{array}$ & $\begin{array}{c}\text { 2 Quarter } \\
\text { Avg. Growth }\end{array}$ & $\begin{array}{c}\text { Per Capita } \\
\text { Avg. GDP } \\
\text { Growth }\end{array}$ \\
\hline Q1 2012 & 51.7 & 56.6 & 57.8 & 0.1 & 0.2 & 0.9 & 0.0 \\
\hline Q2 2012 & 58.1 & 57.7 & 62.4 & 0.9 & 0.3 & 0.5 & 0.1 \\
\hline Q3 2012 & 52.1 & 57.1 & 55.9 & 0.2 & 0.2 & 0.5 & $\mathbf{- 0 . 2}$ \\
\hline Q4 2012 & 52.0 & 51.0 & $\mathbf{4 7 . 1}$ & 0.5 & 0.1 & 0.3 & $\mathbf{- 0 . 2}$ \\
\hline Q1 2013 & 64.7 & 65.0 & 69.9 & 0.3 & 1.0 & 1.1 & 0.8 \\
\hline Q2 2013 & 56.4 & 62.6 & 59.2 & 0.3 & 0.5 & 1.4 & 0.2 \\
\hline Q3 2013 & 63.2 & 62.6 & 65.4 & 0.2 & 0.8 & 1.2 & 0.4 \\
\hline Q4 2013 & 57.1 & 61.3 & 57.5 & 0.2 & 0.9 & 1.6 & 0.5 \\
\hline Q1 2014 & 57.6 & 54.7 & 56.9 & 0.1 & 0.2 & 1.1 & 0.0 \\
\hline Q2 2014 & 60.4 & 59.8 & 64.4 & 0.0 & 1.0 & 1.1 & 0.7 \\
\hline Q3 2014 & 53.8 & 55.8 & 54.9 & 0.2 & 0.4 & 1.4 & 0.1 \\
\hline Q4 2014 & 56.9 & 57.2 & 57.5 & 0.4 & 0.7 & 1.1 & 0.3 \\
\hline Q1 2015 & 53.6 & 53.2 & 52.6 & 0.2 & $-\mathbf{0 . 2}$ & 0.5 & $\mathbf{- 0 . 3}$ \\
\hline Q2 2015 & 55.8 & 57.0 & 56.2 & 0.2 & $\mathbf{- 0 . 1}$ & $\mathbf{- 0 . 3}$ & $\mathbf{- 0 . 2}$ \\
\hline Q3 2015 & 53.5 & 52.9 & 55.6 & 0.2 & 0.6 & 0.5 & 0.3 \\
\hline Q4 2015 & 62.9 & 59.3 & 68.0 & 0.2 & 0.1 & 0.8 & $\mathbf{- 0 . 2}$ \\
\hline Source: Author's calculations. & & & & & & & \\
\hline
\end{tabular}




\section{References}

Conference Board of Canada. 2012. How to Compute Diffusion Indexes. https://www.conference-board.org/data/bci/index.cfm?id=2180.

Cross, Philip. 2004. “A Diffusion Index for GDP.” Canadian Economic Observer vol. 17, no.5.

Cross, Philip, and Philippe Bergevin. 2012. Turning Points: Business Cycles in Canada since 1926. Commentary 366. Toronto: C.D. Howe Institute.

Mitchell, Wesley Clair. 1913. Business Cycles. University of California Press, Berkeley.

Statistics Canada. 2009. “The Canadian Manufacturing Sector: Adapting to Challenges”. Economic Analysis Research Paper Series (11F0027M), no. 57.

This E-Brief is a publication of the C.D. Howe Institute.

Jeremy Kronick is Senior Policy Analyst at the C.D. Howe Institute.

This E-Brief is available at www.cdhowe.org.

Permission is granted to reprint this text if the content is not altered and proper attribution is provided. 